\title{
PSYCHIATRIC MORBIDITY IN CHILDREN WITH CHRONIC MEDICAL ILLNESS: A CROSS SECTIONAL STUDY IN KALAWATI SARAN CHILDREN'S HOSPITAL, NEW DELHI
}

\author{
Das $\mathbf{M}^{*}$, Rathore $\mathbf{R}^{*}$, Dutta A K
}

\section{ABSTRACT}

Psychiatric morbidity is common in the medically ill children, although it is frequently unrecognized and untreated. This study was conducted to determine the nature and extent of psychiatric morbidity in children with chronic medical diseases. 100 children attending the different follow-up clinics at a tertiary care pediatric referral Centre were evaluated using Childhood Psychopathology Measurement Schedule (Malhotra et.el.1988). Thirty one percent children showed abnormally high levels of emotional and behavioral problems indicative of a possible psychiatric disorder. Attendance at Pediatric OPD was associated with an increased risk of common type of childhood psychiatric problems with about $21 \%$ children scored abnormally high in factor III (Anxiety) \& VII (Physical illness with Emotional problems) suggestive of a definitive psychological disorder. The result indicates that about $1 / 3$ rd children attending pediatric follow-up clinics with chronic medical illness need a formal psychiatric evaluation for certain psychological disturbances. This also advocates the provision of a hospital based pediatric psychiatric liaison service that would help to address this need and create opportunities for pediatricians to train in child psychiatry.

\section{Key Words: Psychiatric morbidity; children; chronic medical illness.}

\section{INTRODUCTION}

Chronic illnesses in children interfere significantly with the child's physical and emotional growth and development; therefore a thorough appreciation of the psychological aspects of such diseases in children and adolescents is needed. ${ }^{1}$

In addition to their physical condition, children and adolescent with chronic illnesses must cope with their own emotional reactions to the illness and its care as well as to the reactions of family members, friends, teachers and others. ${ }^{2}$ Factors such as poverty, family structure, and parental characteristics can also exert important influences upon behavior problems in children, ${ }^{3}$ through a wide variety of etiologic mechanism.
A parent's low level of education could be associated with poor parenting skills, which in turn could lead to behavior problems in children. ${ }^{4}$

Risks of social maladaptation and psychological well-being have also been linked to family structure -in particular, femaleheaded single-parent families - among children with and without chronic conditions. ${ }^{1,5}$

Many studies have shown that chronic diseases predispose children to different psychiatric disorders that may have a significant effect on the outcome and cost of medical care. For example, depression is highly prevalent in medically ill adults and this co morbid psychiatric disorder presents complex diagnostic and treatment problem for the chronic medical illness. ${ }^{6,7}$

* Kalawati Saran Children's Hospital, Lady Hardinge Medical College, New Delhi - 110001, India.

Address for correspondence : Dr. Mrinmay Das

Department of Psychiatry

Lady Hardinge Medical College \& associated Hospitals, Bangla Sahib Marg

New Delhi 110001, India.

Email: mrinmaydas@indiatimes.com 


\section{Procedure:}

Hundred children fulfilling the inclusion (chronic medical illness of 1 year or more duration, age: 6 to 14 years of both sexes, parents willing to give informed consent) and exclusion (patients with suspected mental retardation, history of psychiatric illness in the first-degree relative, severely ill patients, history of substance abuse) criteria were recruited serially from various special follow-up clinics of Kalawati Saran Children's Hospital for the study.

Study subjects were evaluated on the day of recruitment. A few inpatients were also evaluated towards the end of their hospital stay, when their medical illnesses became stabilized.

Seriousness of the medical conditions was determined by measuring duration of illness, number of hospitalizations, duration of stay in hospital, repeated invasive procedures and limitations of activities: Children and adolescents were reported to have one of 3 levels of activity limitations due to chronic conditions as defined by the National Center for Health Statistics (NCHS, 1981) ${ }^{21}$ depending on the extent to which their activities are limited as a result of chronic conditions-

Grade I: Unable to carry on major activities, which, for pre school children is taking part in ordinary play with other children, and for school age children, is the inability to go to school, Grade II: Limitations in amount or kind of major activity, which, for pre school children is a limitation in the amount or type of play with other children and for others, it is a limitation to certain types schools or limitations in school attendance including special school, or restrictions on time spent in school Grade III: No limitations in major activity but otherwise limited.

Psychiatric assessment was done by a psychiatrist or by a pediatrician specially trained for psychiatric assessment using a structured interview schedule.

Non-psychiatric interviewer were trained in using the assessment schedule, first by observing the interview by an experienced interviewer, then by conducting a joint interview. Inter rater reliability was also established and then the nonpsychiatric interviewers were allowed to assess independently.

\section{RESULT}

\section{Sociomographic profile of the study subjects (n-100):}

The above table I shows that children included in the study were 6 to 14 years of age with average age being 9.28 yrs, boys predominating with $68 \%$, formal education till $5^{\text {th }}$ standard for maximum no of children $(60 \%)$. Most of the

Table I : Sociomographic profile of the study subjects $(n=100)$

\begin{tabular}{|c|c|c|c|c|c|}
\hline \multicolumn{6}{|c|}{ Age (yrs \%) } \\
\hline $6-8 \%$ & 44 & \multicolumn{2}{|c|}{ Family Informations } & \multicolumn{2}{|c|}{ Education of Informations } \\
\hline $9-11 \%$ & 34 & Mother & 31 & Never been to school & 25 \\
\hline $12-14 \%$ & 22 & Father & 45 & Till $5^{\text {th }}$ standard & 30 \\
\hline Average Age & 9.28 & Other & 24 & $5^{\text {th }}-10^{\text {th }}$ standard & 27 \\
\hline \multicolumn{2}{|l|}{$\operatorname{Sex}(M / F)$} & \multicolumn{2}{|l|}{ S/E status } & High school & 3 \\
\hline Male (\%) & $68(68 \%)$ & Lower Income group & 70 & Graduate & 15 \\
\hline Female $(\%)$ & $32(32 \%)$ & Middle class & 27 & \multicolumn{2}{|l|}{ Occupation } \\
\hline \multicolumn{2}{|l|}{ Education } & Upper class/LM & $0 / 3$ & Unemployed & 17 \\
\hline Never been to school & 31 & Resident & & Labor & 50 \\
\hline Till $5^{\text {th }}$ standard & 60 & Urban & 48 & Service & 18 \\
\hline $5^{\text {th }}-10^{\text {th }}$ standard & 9 & Rural & 52 & Business & 15 \\
\hline
\end{tabular}

Table II : Chronic Medical illness Data profile of the study subjects $(n=100)$

\begin{tabular}{l|cc|c}
\hline $\begin{array}{c}\text { Name of the illness } \\
\text { (number) }\end{array}$ & $\begin{array}{c}\text { Duration of illness } \\
\text { (years) }\end{array}$ & $\begin{array}{c}\text { No. of hospitalization } \\
\text { (Avg.) }\end{array}$ & $\begin{array}{c}\text { Duration of hospitalization } \\
\text { (Days) }\end{array}$ \\
\hline All (6) & 1.8 & 21.2 & 133.0 \\
\hline APA (7) & 1.8 & 20.2 & 127.8 \\
\hline Ch.ITP (2) & 4.0 & 40.5 & 93.4 \\
\hline Asthma (15) & 2.5 & 20.5 & 120.0 \\
\hline Pul. Haemo (1) & 7.0 & 10.0 & 69.6 \\
\hline CLD (11) & 3.7 & 3.7 & 50.4 \\
\hline CD (14) & 2.8 & 5.9 & 42.6 \\
\hline CRF (16) & 3.6 & 9.7 & 40.7 \\
\hline DM (5) & 3.4 & 8.7 & 88.7 \\
\hline HL (3) & 3.5 & 9.6 & 24.0 \\
\hline MAS (5) & 3.5 & 9.5 & 53.5 \\
\hline NS (15) & 3.5 & 7.2 & $\mathbf{6 6 . 1 7}$ \\
\hline \multicolumn{1}{c|}{ Average } & $\mathbf{3 . 4 2}$ & $\mathbf{1 4 . 5}$ & \\
\hline
\end{tabular}


Table V : Distribution of CPMS subscale scores among the study subjects

\begin{tabular}{|c|c|c|c|c|c|c|}
\hline \multirow{2}{*}{\begin{tabular}{l}
\multicolumn{1}{c|}{$\begin{array}{c}\text { CPMS-Subscale } \\
\text { Score }\end{array}$} \\
Factor - I \\
(Low intelligence)
\end{tabular}} & \multirow{2}{*}{$\begin{array}{c}\text { Max. } \\
\text { Score }\end{array}$} & \multicolumn{4}{|c|}{ Max. Score achieved/No. of Subjects } & \multirow{2}{*}{$\begin{array}{c}\begin{array}{c}\text { Min. Score } \\
\text { achieved/No. } \\
\text { of Subjects }\end{array} \\
0 / 43\end{array}$} \\
\hline & & $2 / 19$ & $1 / 33$ & & & \\
\hline $\begin{array}{l}\text { Factor - II } \\
\text { (Conduct disorder) }\end{array}$ & 17 & $9 / 1$ & $4 / 4 \quad 3 / 7$ & $2 / 20$ & $1 / 28$ & $0 / 38$ \\
\hline $\begin{array}{l}\text { Factor - III } \\
\text { (Anxiety) }\end{array}$ & 5 & $3 / 13$ & $2 / 24 \quad 1 / 25$ & & & $0 / 31$ \\
\hline $\begin{array}{l}\text { Factor - IV } \\
\text { (Depression) }\end{array}$ & 13 & $7 / 1$ & $\begin{array}{ll}5 / 6 & 4 / 8\end{array}$ & $3 / 13$ & $\begin{array}{ll}2 / 19 & 1 / 11\end{array}$ & $0 / 30$ \\
\hline $\begin{array}{l}\text { Factor - V } \\
\text { (Psychotic symptoms) }\end{array}$ & 9 & $1 / 17$ & & & & $0 / 74$ \\
\hline $\begin{array}{l}\text { Factor - VI } \\
\text { (Special symptoms) }\end{array}$ & 5 & $2 / 13$ & & & & $0 / 56$ \\
\hline $\begin{array}{l}\text { Factor - VII } \\
\text { (Physical illness with } \\
\text { Emotional problems) }\end{array}$ & 4 & $3 / 10$ & $1 / 34$ & & & $0 / 45$ \\
\hline $\begin{array}{l}\text { Factor - VIII } \\
\text { (Somatization) }\end{array}$ & 6 & $3 / 3$ & $1 / 15$ & & & $0 / 74$ \\
\hline
\end{tabular}

score. Almost $3 / 4$ th subjects scored nil in factor V (Psychotic symptoms) and factor VIII (Somatization).

\section{DISCUSSION}

In our study, $31 \%$ children attending a wide range of pediatric clinics showed abnormally high levels of emotional and behavioral problems indicative of a possible psychiatric disorder. This compares closely with rates obtained in large pediatric samples in the $\mathrm{USA}^{22,23}$ and $\mathrm{UK}^{24,25}$

Children in the present study had twice the rate of psychiatric morbidity compared to community controls diagnosed by parent questionnaire. This corresponds with previous research that suggests that the risk of psychiatric disorders is approximately double in children with physical illness. ${ }^{26,27}$ Attendance at pediatric OPD was associated with an increased risk of common type of child psychiatric problems with about $21 \%$ children scored abnormally high in factor III (Anxiety) \& VII (Physical illness with Emotional problems) (more than $50 \%$ score) suggestive of a definitive psychological disorder.

Whether this increased risk of psychological morbidity was depending on any socioeconomic or demographic characteristics of the household could not be commented upon as most of the children belonged to poor socioeconomic status family. Though 20 out of 31 probable psychologically disordered children were males, but this variability might be a sampling bias because children attending these clinics are mostly males. This might also reflect the gender bias of the Indian society showing less care and attention towards female children.
As far as the limitation of activity as an indicator of severity of chronic medical illness is concerned, around $2 / 3^{\text {rd }}$ had major limitations in activity. This major limitation is more frequently noticed in children suffering from chronic hematological and respiratory disorders, but suspected psychological morbidity is noticed more in children suffering from chronic renal and gastrointestinal disorders. This apparent discrepancy between activity limitations and psychological morbidity might be due to the fact that primary medical conditions, not the associated psychological morbidity responsible for limitations in major activity which again validates the utility of this scale as a measure of severity of a chronic medical illness apart from duration of illness, duration of hospital stay, total no admissions and invasive procedures.

Main strength of the present study is the use of a wellstandardized questionnaire and recruitment of a representative sample. The use of clinic samples could be seen as a weakness if the principle aim was to establish the risk of psychiatric disorders associated with physical illness free of possible referral bias. However, the aim of the present study was specifically to describe the risk among children attending pediatric clinics, with view to establish the need for psychiatric liaison services.

Taking 10 as a cutoff score on CPMS scale for a possible psychiatric disorder is open to criticism, as the children were not individually assessed for formal psychiatric diagnosis.

The main implications of the study are the need to recognize the increased risk of emotional and behavioral disturbances 
